1. Write to the College Entrance Examination Board for free materials on the Advanced Placement Program. [Also see the December 1958 issue of THE bULletin on "Advanced Placement Programs in Secondary Schools."]

2. Pursue in-service study of other plans for stimulating abler students (and others) to work independently.

3. Provide the flexibility in classroom procedures and in scheduling classes essential to successful pursuit of independent study.

4. Provide suitable project centers and smaller spaces for independent study. (See "Space for Individual Learning," The School Executive, February 1959.)

5. Popularize the idea through suitable recognition at school and in the local press.

The steps suggested above should prove the statement made at the outset: Any school that has the desire to get greater returns from its efforts and is willing to try out a few emerging practices will find little difficulty in getting started.

\title{
HOW MUCH AND WHAT KIND OF TESTING PROGRAM FOR TODAY'S SECONDARY SCHOOL?
}

Chairman: S. P. Hyder, Principal, High School, Elizabethton, Tennessee Discussant:

Guy Salyer, Professor of Education and Psychology, Stout State College, Menomonie, Wisconsin

\section{Summary of the presentation made by ROBERT L. FOOSE}<smiles>[Mg]</smiles>

ISS Derby, please make a note for today's bulletin to students: 'Results of the PSAT have arrived and may be reviewed in the guidance office.' Be sure, too, to include a reminder that last month's College Board test scores have come and are now available. The deadline for next month's College Board applications will be the first of next week, so they will need to be reminded again to pick up the forms, and, I almost forgot, we have been asked to notify students that Secondary-School Admissions Tests also will be given here. Incidentally, are we distributing our midyear examination schedule today?"

Robert L. Foose is Principal of Westfield Senior High School, Westfield, New Jersey. 
A fictional picture? Not at all! The calendar of thousands of secondary schools at mid-point in the school year would match it. In actual fact, the same week, in the same school saw plans being made for special National Honor Society scholarship tests, preliminary announcements of registration for National Merit Tests, administration of batteries of aptitude tests in the school by the testing bureau of an engineering college and the U.S. Employment Service, and meetings of the testing committee to consider which tests to consider under the National Defense Education Act. All the while, guidance counselors and the school psychologists were continuing individual testing of students referred to them, the mails continued to carry notices of new tests and testing programs from old and new agencies, and the teachers in the classroom were continuing their daily quizzes, unit tests, and final examinations.

If the picture were to be completed, it would be necessary to paint in such details as long negotiations with the board of education to provide more clerical help to record the mountainous backlog of test scores on permanent records, the efforts of supervisors to help teachers overcome their lethargy toward the interpretation and use of the results of tests with which they have not been directly involved, and the countless questions directed towards the school by parents and students about tests they read about in last Sunday's paper.

There can be no doubt about the growing interest and concern on the part of the public and the schools as to the extent and purpose of testing today and of the regional and national testing programs entering the picture in ever greater numbers. How they are affecting the programs of individual schools is a subject which is generating a great deal of heat and hopefully some light.

In considering the question "How much and what kind of testing programs for today's secondary school," it is easy to lose sight of two basic facts. The first is that public education in America is committed to a bold dream unknown before in human history-to provide educational opportunities for all the children of all the people. Based on the conviction that each individual possesses human worth and dignity and must have the opportunity to develop his greatest potential, a free people has undertaken to educate the masses as the only hope for the betterment of mankind. If our rapidly expanding testing programs can help the schools to achieve that goal, they are eminently worth while. If they result in the elimination or rejection of all but the academically able, they can dangerously affect the realization of this dream.

The second is that a testing program is built into every secondary-school program with its constant pupil evaluation by teacher-made tests. One of the prime concerns of educators today is how to help teachers construct and use their own tests more effectively. Scientific studies of learning have long since shown that tests are one method a teacher may employ to assess status and need, but can wreak devastating effects upon children 
when they are used to judge them rather than to help them learn. One of the real challenges to secondary education is the development of an evaluation program which encourages independent thinking rather than rote memorization, and that regards evaluation as an aid to learning rather than a block or barrier to further progress in an educational pattern which we say is designed to serve all American youth.

Fortunately there are many indications that the schools of this country are committed to developing programs that will meet the needs of all secondary-school-age youth. The growing numbers and the rising proportion of this age group in secondary schools means that the schools are attempting to cope with the problems of mass education, with the proper offerings for the brightest and the least academically able pupils. The work that is being done at all levels, from the local to our national associations, reveals the concern being felt about the use and misuse of testing. More materials are being provided in a swelling stream to help teachers develop in-service training on the effective use of evaluative measures they can develop to assist them in the educative process.

At this point the multiplicity of commercial objective tests and large scale programs can provide real help to the schools, but also can become a real danger to our American system of education. With the benefit of national promotion, many tests can successfully confuse the public which supports the educational system and even the teachers in our schools as to what they can do. If they are used to provide premature and inflexible labels on students, to provide a basis for comparing the quality of the programs of individual schools, to produce a standard curriculum in all the schools of the country, even to provide an evaluative measure which will separate those who should be educated from those who are to be rejected, or to interfere with the ordered pattern of education in the schools, they can be a serious threat to the American secondary school. There is evidence that all of these results have occurred to some degree.

Testing for testing's sake is worthless. Testing for learning's sake is extremely valuable. Herein lies the answer to the question, "How much and what kind?"

School systems which attack the problem realistically have recognized that certain criteria must be applied: What desirable and meaningful information about students can be supplied by tests? What tests are readily available? Are scores readily understood and meaningful in working with students? Are tests valid and acceptable to the teachers using them? Can they be administered fairly, economically, and efficiently? Most importantly, will they be used?

In this test-conscious decade, secondary schools face the challenge of devoting considerable study to their testing programs. A cooperative project with administrators, teachers, and consultants working together should provide the answers to the best kind of in-service training which will be heplful to teachers in improving their own evaluative procedures 
and the selection of standard tests to be administered. Such local testing committees should be prepared to help teachers understand the value of test scores and to interpret them in relation to their teaching. It should point up the value of many of the tests which both secondary teachers and college admissions officers expect to have-a series of intelligence, reading comprehension, academic achievement, and college aptitude tests,-to name a few.

As to the tests imposed, and that word is used advisedly, by outside agencies, schools are rapidly being forced to certain decisions. To avoid interference with the school program, many are now being offered on days not on the school calendar. Schools are learning from experience, which are desirable or necessary for specific purposes; i.e., college admissions, scholarships, etc., and which they can reasonably accept or reject. In the meantime some constructive suggestions are being considered by agencies which are involved with the growing number of widely used examinations. Frank Bowles' proposal that one or two days each term be set aside for administering the host of scholarship and college admission tests now being offered is a suggestion that merits real study.

Fortunately schools in this country still retain their freedom to decide how much and what kind of testing programs to have in their own schools to meet the needs of their pupils. It is a freedom to be cherished at all costs if our dream of universal education is to be achieved.

\section{Summary of the presentation made by CLYDE VROMAN}

B ECAUSE this topic also is discussed by a high-school principal, I am limiting my remarks to the points of view of the colleges. In higher education, we are observing with much interest, and considerable sympathy and concern, the increasing problems and responsibilities of the secondary schools under the impact of current pressures of large-scale testing programs at the state and national level. Most of these test programs are directly connected with the college-level programs of scholarships, admission, pre-enrollment counseling, and placement in college courses. No small portion of the trends is due to our national concern that we find and educate all our talented young people. I will state briefly what the colleges would like to see included in school testing programs. I also will make some suggestions on the broad structure of such programs and the leadership which secondary schools should take as soon as possible.

Colleges hope that each school system will have a comprehensive testing program covering all twelve grades for the supplementary guidance and

Clyde Vroman is Director of Admissions at the University of Michigan, Ann Arbor, Michigan. 
evaluation of pupil growth and for use in the study of the curriculum. By the time a pupil completes his elementary education, the school should have a good understanding of his intelligence, reading level, subject achievements, special abilities, and interests. By the end of the tenth grade, the high school should have similar but up-to-date information on the pupil, plus an understanding of his current interests, potential for post-high-school education, and possible vocational alternatives.

The eleventh grade is the ideal year to collect and coordinate the test data that is useful in helping the student decide whether he should go to college, the programs he may wish in college, and the types of colleges most appropriate for him. Participation in one or more of the current national programs is a constructive and worth-while way for a student to procure helpful test data during his eleventh grade.

During the twelfth grade, the school should gather achievement test data on each senior. Also during this year, the student interested in entering a college, and possibly requesting financial aid, should participate in one or more of the national testing programs. Meanwhile, the school and the college, cooperatively, should be using the available test data on the student to supplement and interpret his school record in counseling him about his plans for a college education.

All this implies that the school will participate in at least some of the current testing programs offered by external agencies. There is criticism that the school does not want and should not participate in any testing program designed for a specialized group such as the college-bound students. And yet many high schools administer the General Aptitude Test Battery of the U. S. Employment Service in order to help a special group-those students interested in entering a vocation immediately following graduation.

From such needs, practices, and trends as given above, it is clear that for some time there will be not only as many but probably more testing programs organized and conducted by groups outside the individual school systems. Each secondary school now can readily procure professional assistance in developing its own program of testing. The crucial need is to develop points of view and programs by which secondary schools individually, and collectively through their state and national associations, can make best use of the external testing programs.

Looking from the eyes and experiences of a college admissions officer, I make the following suggestions to the secondary schools as a basis for organizing a constructive approach to deal with the present dilemma posed by multiple testing programs:

First, each secondary school must have an adequate guidance and counseling program and staff, including the specialized services needed by students with ability to profit from a college education. 
Second, the school should organize to participate effectively in state and national testing programs insofar as such programs are useful or desired by students.

Third, the school should integrate the data from the external testing programs with its own testing programs and interpret the findings for students, parents, and teachers.

Fourth, the school should make cooperative follow-up studies of its students to learn the relationships of test data to subsequent student experiences. This is particularly urgent and possible between the school and one or more colleges in which a substantial number of the school's graduates regularly enroll.

Fifth, the school should prepare summaries of the test data to submit to the colleges as a part of the "school characteristic" statement which should accompany each student's application for admission. In addition, the school should interpret the individual student's test scores in terms of school and national norms.

Sixth, I urge that the secondary schools individually, and collectively under the leadership of the NASSP, formulate a statement or code of recommended points of view, policies, and practices aimed directly at (1) eliminating the undesirable and negative attitudes and practices relating to external testing programs, and (2) developing desirable attitudes, policies, and practices in all matters pertaining to such testing programs.

We frequently hear criticisms of large-scale testing programs-“They will all lead to Federally controlled examinations; teachers will teach for the tests; private coaching schools will flourish; tests will control the curriculum and teaching methods; college admissions will depend on minimum test scores; schools will be rated by the public; pupils will be classified and channeled too early; tests do not measure everything; test administration interferes with teaching and classroom experiences," etc. Such criticisms may have been valid a few decades ago in the conditions which existed at that time. However, conditions have changed greatly and such weaknesses will exist now only if we permit them by our failure to take positive and constructive action.

It is most urgent that we initiate a program (1) to forestall the possible evils that might accompany participation in large-scale testing programs, and (2) to implement the desirable outcomes and values of those programs. I am confident that principals and their schools can reduce greatly the negative effects of external testing programs and can initiate practices which will make the positive values far outweigh their negative potentials. State and national testing programs then will make their proper contribution to testing programs for today's secondary schools. 